\title{
Plasmalogen lipids: functional mechanism and their involvement in gastrointestinal cancer
}

\author{
Márcia Cristina Fernandes Messias*, Giovana Colozza Mecatti, Denise Gonçalves Priolli \\ and Patrícia de Oliveira Carvalho*
}

\begin{abstract}
The plasmalogens are a class of glycerophospholipids which contain a vinyl-ether and an ester bond at the sn-1 and sn-2 positions, respectively, in the glycerol backbone. They constitute $10 \mathrm{~mol} \%$ of the total mass of phospholipids in humans, mainly as membrane structure components. Plasmalogens are important for the organization and stability of lipid raft microdomains and cholesterol-rich membrane regions involved in cellular signaling. In addition to their structural roles, a subset of ether lipids are thought to function as endogenous antioxidants and emerging studies suggest that they are involved in cell differentiation and signaling pathways. Although the clinical significance of plasmalogens is linked to peroxisomal disorders, the pathophysiological roles and their possible metabolic pathways are not fully understood since they present unique structural attributes for the different tissue types. Studies suggest that changes in plasmalogen metabolism may contribute to the development of various types of cancer. Here, we review the molecular characteristics of plasmalogens in order to significantly increase our understanding of the plasmalogen molecule and its involvement in gastrointestinal cancers as well as other types of cancers.
\end{abstract}

Keywords: Plasmalogen, Cancer, Lipidomic, Biomarker

\section{Background}

Lipids, especially phospholipids (PL), are extremely diverse molecules and act as regulators of various cellular functions such as homeostasis, cell adhesion and migration, neurotransmission, signal transduction, vesicular trafficking, apoptosis and post-translational modification [1]. Among the lipids, the categories that have the most important roles in the membrane structure are glycerophospholipids (GPL), sphingolipids, sterols and triglycerides [2]. Several studies have shown that the interruption of lipid metabolism is related to the onset and severe progression of some types of human cancers [3]. Recent discoveries in the modulation of essential lipid enzymes, signaling lipid molecules and global lipid metabolism alteration in aggressive progression of cancer have fundamentally expanded our perception of lipid metabolism and its impact on tumor etiology. Rewiring

\footnotetext{
* Correspondence: marcia_cfmessias@hotmail.com: patricia.carvalho@usf.edu.br

Laboratory of Multidisciplinary Research, São Francisco University, USF, São Francisco de Assis Avenue, 218, Bragança Paulista, SP 12916-900, Brazil
}

of metabolic programs, such as aerobic glycolysis and increased glutamine metabolism, are crucial for cancer cells to shed from a primary tumor, overcome the nutrient and energy deficit, and eventually survive and form metastases [4].

Biomarkers can be employed for (early stage) diagnosis of cancer, prognosis (assessing lethality) and prediction 117 (of patient's response to treatment). Some PL have been described in the literature as potential biomarkers for cancer, among them the plasmalogens, a subclass of GPL $[5,6]$. Plasmalogens were discovered accidentally in 1924 by Feulgen and Voit [7] while staining sections of tissue with a nuclear dye that reacted with the aldehydes released by DNA acid hydrolysis [8]. Structurally plasmalogens exhibit a vinyl ether at the $s n-1$ position of glycerol, play several roles in cellular function and are an important component of the cellular plasma membrane [9]. Although the mechanisms of action for plasmalogens remain unclear, they are starting to receive medical interest as they are now being linked to Alzheimer's disease, Down syndrome, molecular signaling abnormalities 
and cancer. Plasmalogens are linearly correlated with metastases spreading in vivo. Therefore, they can be useful in the prognosis of the most frequently observed human cancers, particularly in pathological colorectal, breast, lung and prostate tissues.

Among the organ cancers, gastrointestinal (GI) cancers present an interesting pattern in their global distribution. GI cancers is a term for the group of cancers that affect the digestive system and includes gastric, colorectal, intestinal, hepatocellular, esophageal and pancreatic cancers [10]. According to the World Health Organization [11], in 2015 cancer caused 8.8 million deaths worldwide. Among the types of cancer deaths, the most common are lung cancer (1.69 million deaths), liver $(788,000$ deaths), colorectal $(774,000$ deaths), stomach (754,000 deaths) and breast (571,000 deaths). The incidence of cancer is increasing not only because of the limited understanding of its pathophysiology, but also because there is a restriction on access to prevention, treatment and prognosis of the disease for most patients [12]. Early detection of cancer through diagnostic, prognostic and predictive biomarkers represents a promising field of research in the identification of early stage cancer and in personalized therapies. Although recent studies have identified a few molecular biomarkers that may detect GI cancer at its early stage and progression, there is still a large gap that needs to be addressed to improve its screening, prevention and treatment [13].

Lipidomic analysis can also provide information about the nature of cell dysfunction and help identify the underlying metabolic pathways and molecular mechanisms of disease [9]. To date, analytical strategies have been applied to a wide variety of biological samples such as blood, plasma, serum, cerebrospinal fluid, urine and biological tissue derived from animal models or clinical patients [14]. Lipidomic analyses make it feasible to characterize the tumor, detect and, classify neoplastic cells and tissues and differentiate between the neoplastic and normal environment and also to evaluate the anticancer treatment (responsiveness and resistance). Consequently lipidomic analysis could lead to the discovery of new tumor biomarkers [15].

The aim of this review is to provide an overview of current knowledge of the biology and pathology of plasmalogens with an emphasis on their involvement in GI cancer. Furthermore a better understanding of plasmalogen biology in cancer could also lead to the development of better diagnostic and prognostic biomarkers or new therapeutic targets for GI cancers.

\section{The lipids in the human body}

In the last decades there has been an intense effort to develop adequate methodologies to discover, identify and quantitatively monitor the lipids of the biological system [16]. They have several key biological functions, such as the activation of the components of the cell membranes, and they serve as a source for energy storage and participate in the autocrine and paracrine signaling pathways and autophagy [17]. This diversity of function is due to the enormous variation and complexity in the structure of their molecules since different biochemical transformations are necessary for their biosynthesis to occur [18].

The Lipid Maps [19] classification system defines the structure of lipids from two types of biochemical subunits or building blocks: ketoacyl and isoprene groups [17]. According to this approach, lipids can be classified into eight categories: fatty acids, glycerolipids, GPL, sphingolipids, saccharolipids and polyketides (derived from the condensation of ketoacyl subunits) and sterol and prenolic lipids (derived from the condensation of isoprene subunits) (Table 1) [12].

The major lipids present in the eukaryotic cell membrane are GPL, sterols and sphingolipids [20]. The major classes of GPL include: phosphatidic acid (PA), phosphatidylglycerol (PG), phosphatidylinositol (PI), cardiolipin and the aminoglycerophospholipids, namely phosphatidylcholine (PC), phosphatidylethanolamine (PE) and phosphatidylserine (PS). GPL are the most abundant in eukaryotic cells and the only subclass of GPL that presents a long chain vinyl ether in the $s n-1$ position of the glycerol moiety is the plasmalogens $[20,21]$. The GPL composition of membranes varies with cell type in multicellular organisms and is different in the individual organelles in eukaryotic cells. Plasmalogens are widely distributed in the biological membrane of animals and certain anaerobic bacteria [22] and appear to be associated with diverse clinical manifestations including metabolic diseases associated with oxidative stress [23] and cancer [5].

\section{Biomarker categories}

According to the Food \& Drug Administration (FDA) [24] a biological marker or a biomarker is defined as a characteristic that is measured as an indicator of normal biological processes, pathogenic processes, or responses to an exposure or therapeutic intervention.

They can be detected in the circulation (whole blood, serum or plasma) or excretion or secretions (stool, urine, sputum or nipple discharge), and thus easily assessed non-invasively and serially, or can be tissue-derived, and require either biopsy or special imaging for evaluation [25, 26]. In oncology, biomarkers have many potential applications inclunding risk, screening, diagnosis, prognosis, prediction and monitoring (Fig. 1) [26]. The six categories of biomarkers have been defined as follows: 
Table 1 Lipid Categories: Representation of the structures of the eight lipid categories [19]

\begin{tabular}{|c|c|c|}
\hline Lipid Categories & Molecular structures & Representative functions \\
\hline Fatty acids & & Major lipid building block of complex lipids. \\
\hline Glycerolipids & & Membrane constituents, metabolic fuels and signaling molecules. \\
\hline Glycerophospholipids & & Components of the lipid bilayer of cells. \\
\hline Sphingolipids & & Formed by a sphingoid base backbone. \\
\hline Sterol lipids & & Important components of membrane lipids and function as hormones. \\
\hline Prenol lipids & & Function as antioxidants. \\
\hline Polyketides & & Commonly used antimicrobial, antiparasitic and anticancer agents. \\
\hline Saccharolipids & & Components of membrane lipids. \\
\hline
\end{tabular}

Biomarker of risk: inherent or acquired ability of the body to respond to exposure to a specific substance [27]. Biomarker screening: early detection of disease in real time [28].

Biomarker diagnosis: identifies whether a patient has a specific disease condition [29].

Biomarker prognosis: informs regarding the risk of clinical outcomes such as disease recurrence or disease progression in the future [30].

Biomarker prediction: predicts response to specific therapeutic interventions [25].

Biomarker monitory: monitors the disease, recurrence and therapeutic response [26].
Although some approaches are performed in lipid analysis, no biomarker with 100\% diagnostic accuracy has been found for any type of cancer because of the heterogeneous nature of the disease. Accordingly, efforts are focused on the search for biomarker panels instead of individual biomarkers [6]. Despite the significant improvements obtained in the last decades in the diagnosis and treatment of cancer, the impossibility of early detection of the disease through reliable biomarkers complicates personalized care for patients with cancer [1]. Reliable biomarkers could also be useful in monitoring and controlling toxicity of antitumor treatment [31].

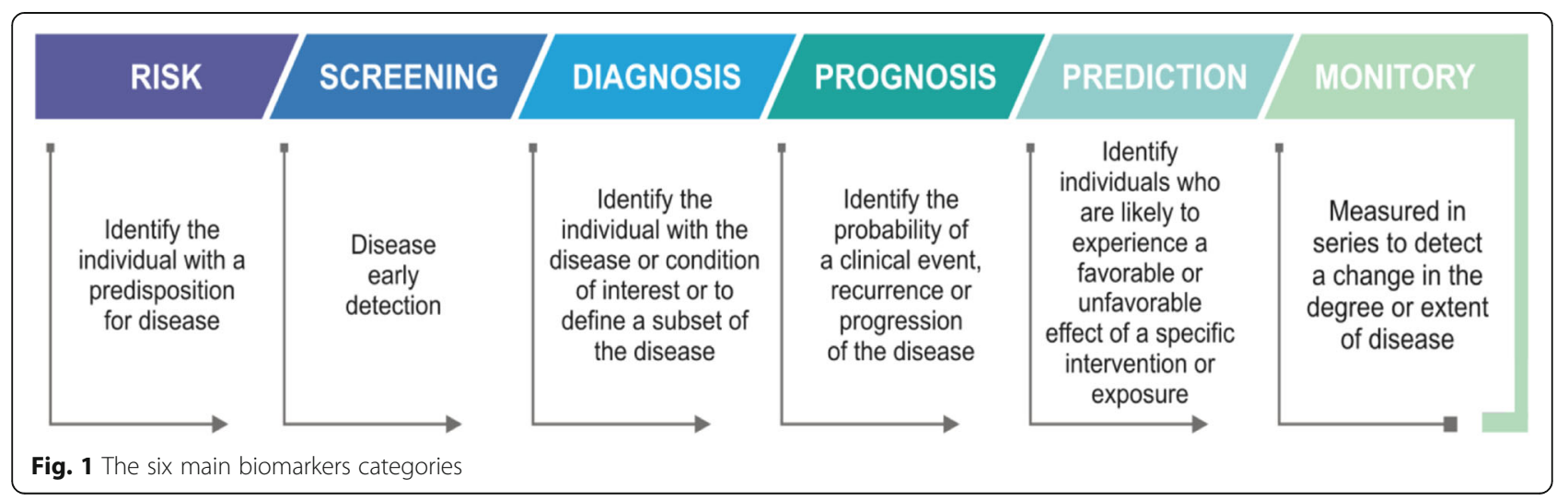




\section{Characteristics of plasmalogens}

Based on the substitution present at the $s n-1$ position of the glycerol structure [32], GPL are divided into three subclasses: acyl, alkyl and alkenyl [33]. The alkenyls formed are called plasmalogens or plasmenyls or 10(1Z-alkenyl)-2-acyl- glycerophospholipids [7]. Plasmalogens are characterized by the presence of a vinyl-ether bond at the $s n-1$ position and an ester bond at thesn-2 position of the glycerol backbone [34, 35]. Other ether PL include plasmanyl PL (containing a saturated ether moiety at the $s n-1$ position), platelet-activating factor (PAF), seminolipid, and partly, the glycosylphosphatidylinositol anchor of membrane proteins. In addition to being present in human biological fluids, plasmalogens are also widely found in anaerobic bacteria, invertebrates and vertebrate animal species [7]. Plasmalogens are characterized by a short half-life: about $30 \mathrm{~min}$ for choline plasmalogens and $3 \mathrm{~h}$ for ethanolamine plasmalogens [36]. The plasmalogens are located in the cell membrane, organelles and lipid rafts and may represent (at least in selected cases) major constituents of membrane lipids; their presence is responsible for characteristic biophysical properties. The perpendicular orientation of the $s n-2$ acyl chain and the lack of a carbonyl group at the $s n-1$ position affect the hydrophobicity of these lipids, causing stronger intermolecular hydrogen bonding between the individual phospholipid molecules [37]. Concerning the biophysical properties, experiments have demonstrated that plasmalogens have lower lamellar gel to liquid-crystalline and lamellar to inverse-hexagonal phase transition temperatures compared to their alky and diacyl counterparts [37-39].

\section{General structures}

In the GPL category, plasmalogens differ from the other components of the class because they have an ether vinyl at the $s n-1$ position of glycerol instead of a fatty acid [7]. To this ether vinyl (R1) are attached the saturated $(\mathrm{C} 16: 0)$ and saturated and monounsaturated carbon chains (C18:0 and C18:1, respectively) [7, 34]. In the $s n-2$ (R2) position, plasmalogens are enriched with polyunsaturated fatty acid, specifically docosahexaenoic acids (C22:6 n-3) or arachidonic acid (C20:4 $\omega-6)$ [40]. As for the $s n-3(\mathrm{X})$ position, plasmalogens are classified mainly as PC plasmalogens (also calledplasmenylcholines) and PE plasmalogens (also called plasmenylethalomines) [23] (Fig. 2).

\section{Distribution among different species}

Plasmalogens are distributed both in the animal kingdom and in certain anaerobic microorganisms [41]. In human cells plasmalogens correspond to $10 \mathrm{~mol} \%$ of the total mass of all PL [35]. In relation to the content of plasmalogens, human tissues and cells may differ significantly in individual values, considering that: lipoproteins contain 5\% [42], myelin 11-12\% [41], heart 32-50\%, brain $20-50 \%$, inflammatory cells up to $50 \%$ and spermatozoa $55 \%$ [43]. In most tissues, ethanolamine is the dominating head group. Choline plasmalogens play an important role in cardiac tissue, but represent a minor species in most other organs. Other head groups, like serine or inositol, are extremely rare. In plasma, specifically, PE and PC plasmalogens represent $50 \%$ of total PE and 5\% of total PC [44]. Zhan et al. [45] point out that the liver has lower amounts of plasmalogens and that this reduction is possibly related to their synthesis in the liver and subsequent transport by the lipoproteins to other tissues.

\section{Biosynthesis}

Peroxisomes are organelles responsible for the activity of several metabolic pathways, including plasmalogen biosynthesis and $\beta$-oxidation of long chain fatty acids [46]. The absence or dysfunction of peroxisomes may be the cause of some human diseases [40].

Synthesis of plasmalogens initiated in peroxisomes occurs in seven steps (Fig. 3) and is terminated in the

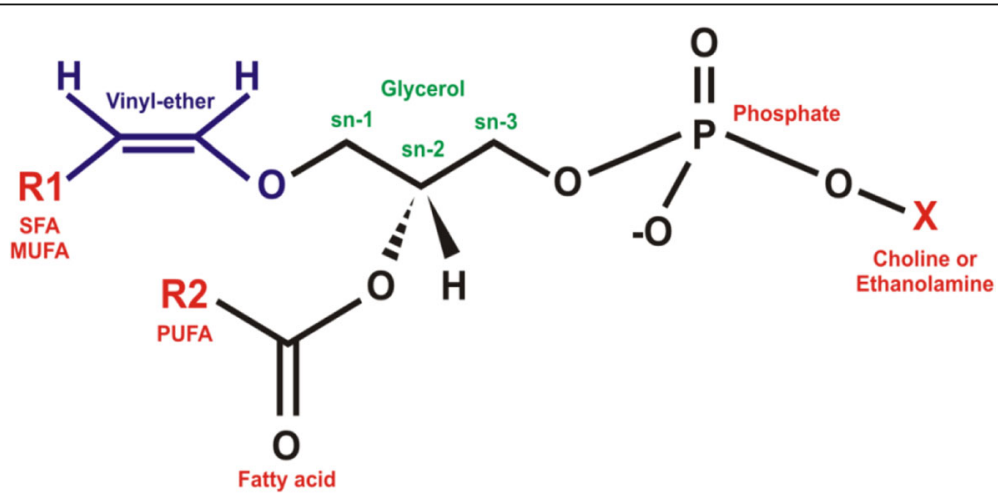

Fig. 2 Structure of plasmalogen. R1: saturated fatty acid (SFA), monounsaturated fatty acid (MUFA); R2: polyunsaturated fatty acid (PUFA); sn-1, sn-2 and sn-3 glycerol position; $X$ : choline or ethanolamine as polar head group 


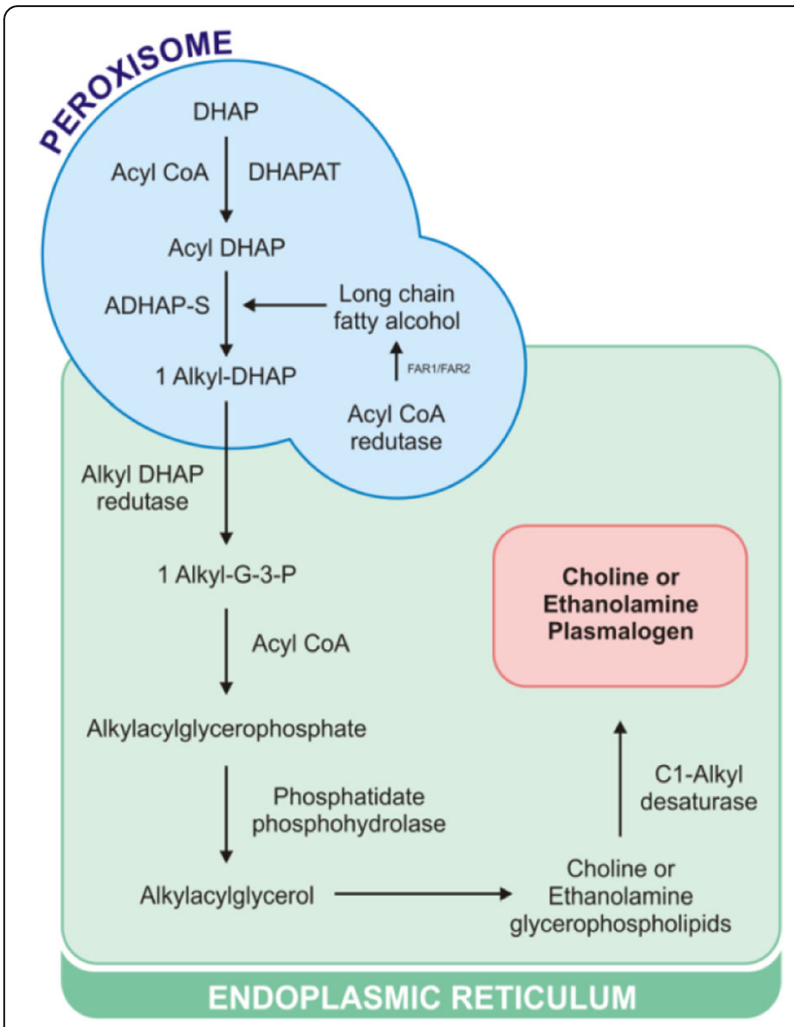

Fig. 3 Schematic representation of the biosynthesis of plasmalogens. See text for nomenclature and abbreviations

endoplasmic reticulum [47]. The process is initiated by the enzyme dihydroxyacetone phosphate acyltransferase (DHAPAT) where dihydroxyacetone phosphate (DHAP) is esterified with a long-chain acyl-CoA ester [48]. In the second step, the alkyl dihydroxyacetone phosphate synthase (ADHAP-S) forms the alkyl DHAP linkage. Out of the peroxisome, the acyl-CoA reductase 1 and 2 (FAR1/FAR2) enzymes provide the fatty alcohol for ADHAP-S [34]. Subsequent steps occur in the endoplasmic reticulum and there is biosynthesis of diacylglycerophospholipids [9]. In the third step alkyl-DHAP is reduced by alkyl-DHAP reductase to form 1-alkylglycerol-3-phosphate/G-3-P) [49]. Then, in the fourth step, 1-alkyl-G-3-P acylation occurs with acyl-CoA to produce alkylacylglycerophosphate [9]. The enzyme phosphatidate phosphohydrolase removes, in step five, the alkylacylglycerol phosphate (diacylglycerol analogue), which will be used in step six as a substrate to produce choline or ethanolamine GPL [41]. In the final step of the biosynthesis, the desaturation of the ether present in these two GPL by the C1-alkyl desaturase leads to the production of choline or ethanolamine plasmalogens $[9,41]$.

Membrane plasmalogen composition is tightly controlled by synthesis, remodeling, signaling induced hydrolysis and degradation. The fatty acyl-CoA reductase provides fatty alcohols used in the formation of alkyl bonds bound to ether [50]. Lysoplasmalogenase, a specific enzyme of the plasmalogens $s n-2$ position, catalyzes hydrolytic cleavage of the vinyl-ether bond of lisoplasmalogen, forming a fatty aldehyde and glycerophosphocholine or glycerophosphoethanolamine [51]. It modulates the properties by similarity of the cell membrane, controlling the levels of plasmalogens and lisoplasmalogen in the cells [52]. Another enzyme that also acts in the $s n-2$ position is Phospholipase A2 (PLA2). It catalyzes the hydrolysis of the $s n-2$ position of glycerol, releasing arachidonic acid, a precursor of eicosanoids (prostaglandins and leukotrienes) and it also produces lysophospholipids [53].

\section{Functions}

Although the role of plasmalogens has not yet been fully elucidated, studies suggest that they have unique functions within the cells and that these are directly related to the bonds of $s n-1$ vinyl ether and $s n-2$ positions of polyunsaturated fatty acids [7]. In addition, plasmalogens can act directly in reducing PL surface tension and viscosity, on the synaptic transmission process, on alveolar surfactants, improving membrane dynamics during respiratory cycles, on signal transduction [48], on membrane vesicle formation, on ion transport, on the platelet activation factor [54], the regulation of fusion, fission and fluidity of the cell membrane, control of membrane proteins activity [35], as a reservoir for second lipid messengers [41] and supporting polyunsaturated fatty acids [55].

Differences between the catabolism of ether GPL by specific phospholipase enzymes might be involved in the generation of lipid second messenger systems such as prostaglandins and arachidonic acid that are important in signal transduction [56]. Ether lipids can also act directly in cell signaling, as the PAF is an ether lipid signaling molecule that is involved in leukocyte function in the mammalian immune system [57].

Plasmalogens play a crucial role as endogenous antioxidants, protecting other PL, lipid and lipoprotein particles from oxidative stress [48]. This is due to the fact that the vinyl ether bond is preferably oxidized, while protecting the polyunsaturated fatty acids present in the $s n-2$ oxidation position [55]. As the hydrogen atoms adjacent to the vinyl ether bond have relatively low dissociation energy, they end up being oxidized when exposed to various oxidizing reagents (peroxyl radicals, metal ions, UV light, singlet oxygen and halogenating species) [58]. Consequently there is consumption of plasmalogens in the reaction and the polyunsaturated fatty acids and other membrane lipids are spared from oxidation, suggesting the role of sacrificial oxidant for plasmalogens [7]. They undergo oxidative decomposition more readily than their fatty acid ester analogues [59]. The oxidative products of plasmalogens are unable to further propagate lipid peroxidation; they may terminate 
the lipid oxidation process [60]. Thus, it is suggested that plasmalogens interfere in the propagation step rather than in the initiation of lipid peroxidation [61]. The product profile resulting from oxidation of plasmalogens will depend on the type of fatty acid esterified in the $s n$ 1 and $s n-2$ positions of glycerol and on the nature of oxidative stress initiators [59]. These products have been used to assess the severity of pathological conditions involving oxidative stress [61]. Plasmalogens, in addition to being prone to the oxidative process, also play a role in the inhibition of iron-induced peroxidation of polyunsaturated fatty acid and in copper-induced oxidation of low density lipoproteins [48]. Thus plasmalogens could have a decisive role in the defense systems against lipid oxidation [62].

\section{Analytical methods to detect plasmalogens}

Several methods for identifying, characterizing and quantifying plasmalogen molecules have been developed with the aim of gaining broader knowledge about lipid ether activity in the pathogenesis of disease [35, 63]. Plasmalogen analysis can be performed through various analytical techniques (chromatography, mass spectrometry and other spectrometric techniques), each with its advantages and disadvantages [40]. Just as with any other lipid, prior to analysis by analytical methods, plasmalogens should normally be extracted using solvents such as chloroform and methanol to remove water-soluble metabolites [64]. The phase obtained with chloroform can be used without the need for purification [40]. It is worth mentioning that any addition of acid should be avoided since plasmalogens are extremely sensitive and can affect the formation of lysophospholipids and aldehydes [65].

Among the chromatographic methods used for plasmalogen analysis are Thin-layer Chromatography (TLC) and High Performance Liquid Chromatography (HPLC) [33]. These techniques, based on relative or absolute quantification and the use of internal standards, help in the identification of different plasmalogen subspecies as well as new plasmalogens [7]. TLC allows several types of samples to be investigated in a single plate [43]. In this method the plasmalogens react with acid dinitrophenylhydrazine (DNPH) leading to their hydrolysis [66]. The aldehyde released in this process is converted to 2,4-dinitrophenylhydrazone, an orange compound, which can be measured densiometrically, determining the plasmalogens content in the sample [40]. A study by Maeba \& Ueta [67] with HPLC using radioactive iodine identified PC and PE plasmalogens in human plasma. Acid hydrolysis of the plasmalogens produces the lysophospholipid and a fatty acid, thus, the plasmalogen measurement is performed by quantifying one of the two products formed by HPLC [68]. Many applications of HPLC quantification for plasmalogen analysis exist and are well documented in the literature [68-70]. Currently, mass spectrometry (MS) and tandem mass spectrometry (MS/MS) methods are being used as tools for lipid analysis. Although MS has a high resolving power and mass precision, it can still be limited since many lipids have the same $\mathrm{m} / \mathrm{z}$ values [71]. Strategies based on GC-MS and LC-MS for the analysis of chlorinated plasmalogen lipids (which are generated in the presence of activated chlorine) were summarized by Wacker et al. [72]. Optimized LC MS/MS conditions using alkali metals make it possible to selectively and sensitively identify $\mathrm{PC}$ and PE plasmalogens at the molecular species level in biological samples (rat brain and heart) [73]. Although a number of different ionization techniques are currently available in lipid research, only two of them play a major role: electrospray ionization (ESI) and matrix-assisted laser desorption and ionization (MALDI). The determination of the molecular weight alone does not provide structural information and tandem mass spectrometry (MS/MS) is normally required. Strategies currently used in lipidomics include direct infusion ESI-MS and ESI-MS/MS and MALDI combined with Fourier transform ion cyclotron resonance MS (MALDI-FTICR-MS) or time-of-flight MS (MALDITOF-MS) [74]. A combination of high-resolution, FI-FTICR-MS and flow-injection tandem mass spectrometry (FI-MS/MS) has been used to identify and confirm specific dysregulated metabolic systems associated with pancreatic cancer in two ethnically and geographically diverse populations [75].

A very simple method to identify plasmalogens in crude lipid extracts has been suggested. The reaction of plasmalogens with acidic dinitrophenylhydrazine (DNPH) directly leads to the hydrolysis of the plasmalogens and the subsequent conversion of the released aldehyde into a 2,4-dinitrophenylhydrazone that is easily detectable in the negative ion MALDI spectrum [66].

Individual GPL classes and even the fatty acyl composition and the linkage type in $s n-1$ position of a given lipid can be differentiated by phosphorus nuclear magnetic resonance spectroscopy ( ${ }^{31} \mathrm{P}$ NMR) [76]. Analysis of the tissue phospholipid extracts by ${ }^{31} \mathrm{P}$ NMR was found to be capable of discriminating between esophageal cancer and adjacent normal tissues, including the noninvolved esophagus and normal stomach [77].

\section{Plasmalogen lipids in gastrointestinal cancer}

Decades ago it was observed that cancer cells have remarkably higher levels of alkyl and alk-1-enyl ethers lipids compared to normal cells [78-81]. Encouraged by these findings, there were efforts trying to establish ether lipids as tumor markers in medical cancer diagnostics. Some studies have also reported decreased amounts of ether lipids in cancer patients $[75,77]$. 
In Table 2 it is possible to evaluate some plasmalogens that were identified in colorectal, gastric, pancreatic and esophageal cancer patients as well as the samples and techniques of lipidic analysis applied.

Although many studies suggest altered plasmalogen production in cancer patients, the mechanism is not yet understood, suggesting a need for future research. It was observed that the plasmalogens can activate phosphatidylinositol 3-kinase, stimulate cell growth, participate in mitogenic responses [82] and have also been correlated with the levels of several oncogenic signaling lipids involved in the regulation of cell survival, cancer aggressiveness and tumor growth [83]. Benjamin et al. [83] reported increased expression of the ether lipid synthetic enzyme ADHAP-S (also called alkylglyceronephosphate synthase, AGPS) in various cancer cell lines and primary tumors. AGPS knockdown impaired experimental cancer pathogenesis, including cell survival, migration, and invasion. The pathogenic impairments conferred by AGPS knockdown in cancer cells are due to the specific depletion of the oncogenic signaling lipid lysophosphatidic acid ether and prostaglandins. The studies indicated that AGPS may serve as an attractive therapeutic target for combatting malignant human cancers, through altering the landscape of oncogenic signaling lipids that drive cancer aggressiveness [84].

Concerning the relationship of plasmalogens and tumors, Merchant et al. [85] reported a statistically significant elevation in the relative concentration of LPC and PC plasmalogens of malignant human colon specimens analyzed by ${ }^{31} \mathrm{P}$ NMR. They also showed that the PE plasmalogens and PS are significantly diminished in esophageal tumors when compared to normal esophageal tissues obtained from the same patients. The data revealed a correlation between decreasing levels of four of the PL (5dihydrosphingomyelin, lysoalkylacylphosphatidylcholine, LPC and phosphatidylglycerol) and increasing tumor aggressiveness as indicated by $T$ stage and tumor grade [77].

According to Dueck et al. [5], alterations in the levels of different subclasses of plasmalogens may be related to the reduction of the activity of the Phospholipases $\mathrm{C}$ and $\mathrm{D}$ and increase of the activity of the phosphocholine cytidyltransferase enzyme in human colon cancer. For Christen et al. [86] the connection between plasmalogens and colorectal cancer can only be hypothesized, since the fluidity in the membrane, provided by plasmalogens, can facilitate the capture of carcinogenic substances, both microbial and via diet. Quantitative chromatographic analysis of the phospholipid content of colorectal carcinoma showed a generally elevated concentration of PL, also including a PE plasmalogen species $(34: 2)$ [87].

Ritchie et al. [75] confirmed the involvement of three major dysregulated metabolic systems in the serum of pancreatic cancer patients: very long-chain fatty acids, choline-containing GPL and PE plasmalogens. Although

Table 2 Principal alkyl and alkenyl glycerolipids identified in Gl cancer patients, the type of tissue sample analyzed and techniques of lipidic analysis employed

\begin{tabular}{|c|c|c|c|c|}
\hline & Samples & Biomarker & Analytical Methods & References \\
\hline Liver & Hepatocellular carcinoma & $\begin{array}{l}\uparrow \text { Neutral 0- } \\
\text { alkylglycerolipids }\end{array}$ & $\begin{array}{l}\text { Gas-chromatographic (GC) and } \\
\text { colorimetric estimation }\end{array}$ & [106] \\
\hline Colon & $\begin{array}{l}\text { Tissue - } 16 \text { malignant human } \\
\text { colon and } 11 \text { non-malignant }\end{array}$ & $\begin{array}{l}\uparrow P C \text { plasmalogen } \\
\downarrow P E \text { plasmalogen }\end{array}$ & $\begin{array}{l}\text { Nuclear magnetic resonance } \\
\text { spectroscopy ( }\left({ }^{31} \mathrm{P} \text { NMR) }\right.\end{array}$ & [85] \\
\hline Colon & Tissue - human colon carcinoma & $\uparrow P C$ and PE plasmalogen & Thin Layer Chromatography (TLC) & [5] \\
\hline Esophageal & $\begin{array}{l}\text { Tissue - } 36 \text { malignant esophageal } \\
\text { tumors }\end{array}$ & $\downarrow$ PE plasmalogen & $\begin{array}{l}\text { Nuclear magnetic resonance } \\
\text { spectroscopy ( }\left(^{31} \mathrm{P} \text { NMR) }\right.\end{array}$ & {$[77]$} \\
\hline $\begin{array}{l}\text { Colorectal cancer } \\
\text { liver metastasis }\end{array}$ & $\begin{array}{l}\text { Tissue - } 40 \text { liver metastases of } \\
\text { colorectal cancers and } 31 \text { primary } \\
\text { colorectal adenocarcinomas }\end{array}$ & $\uparrow P E$ plasmalogen (34:2) & $\begin{array}{l}\text { Desorption electrospray ionization } \\
\text { (DESI) }\end{array}$ & [87] \\
\hline Pancreatic & $\begin{array}{l}\text { Serum - } 40 \text { japanese pancreatic } \\
\text { cancer patients and } 50 \text { controls }\end{array}$ & $\downarrow$ PE plasmalogen & $\begin{array}{l}\text { Flow-injection Fourier transform ion } \\
\text { cyclotron resonance mass spectrometry } \\
\text { (FI-FTICR-MS) }\end{array}$ & [75] \\
\hline Colorectal cancer & $\begin{array}{l}\text { Visceral and subcutaneous } \\
\text { adipose tissue in } 59 \text { CRC } \\
\text { patients (tumor stages I-IV) }\end{array}$ & $\begin{array}{l}\downarrow P C \text { and PE plasmalogen } \\
\text { (P-38:4/ P-36:4/) in visceral } \\
\text { adipose tissue }\end{array}$ & $\begin{array}{l}\text { Gas Chromatography time-of-flight } \\
\text { mass spectrometry (CG-TOF-MS) and } \\
\text { Liquid Chromatography quadrupole } \\
\text { time-of-flight mass spectrometry } \\
\text { (LC-QqTOF-MS) }\end{array}$ & [107] \\
\hline Gastric & $\begin{array}{l}\text { Plasma - } 29 \text { gastric carcinoma } \\
\text { patients and } 30 \text { normal controls }\end{array}$ & $\uparrow$ Plasmalogen & $\begin{array}{l}\text { Method of Svennerholm } \\
\text { (iodine disappearance method) }\end{array}$ & [88] \\
\hline $\begin{array}{l}\text { Colorectal cancer } \\
\text { liver metastasis }\end{array}$ & $\begin{array}{l}\text { Tissue - } 52 \text { liver lesions from } \\
50 \text { patients }\end{array}$ & $\begin{array}{l}\uparrow \text { PE Plasmalogen } \\
\quad(P-16: 0 / 18: 2, P-16: 0 / 18: 1)\end{array}$ & $\begin{array}{l}\text { Matrix-assisted laser desorption/ } \\
\text { ionization mass spectrometry } \\
\text { imaging (MALDI-MSI) }\end{array}$ & [91] \\
\hline
\end{tabular}


most of the individual metabolites showed a significant reduction in PC patient serum, the strongest discriminator based on multiple statistical criteria was PC-594.

In gastric carcinoma patients, the plasma plasmalogens content was significantly elevated and was positively correlated with elevated level of gangliosides and total cholesterols, but it was negatively correlated with level of total PL [88]. Although many studies consistently reported higher concentration of plasma plasmalogens in cancer patients, the mechanism is not yet understood. The mechanism may be that the key plasmalogens enzyme, phosphodihydroxyacetone acyltransferase, strengthens activity [89]. Phosphatidyl cytonucleotide transferase activity can strengthen synthesis of plasmalogen [90].

Patterson et al. [91] identify single lipid moieties that are overexpressed in different histopathological features from colorectal cancer liver metastasis specimens resected from patients preoperatively treated with chemotherapy, which have potential as new biomarkers for assessing response to therapy. Ceramides and plasmalogens were identified in the necrosis areas and made it possible to distinguish between different types of necrosis (usual necrosis and that typical of tumor progression) in tissue specimens that may not be clearly revealed by histopathology. $\mathrm{PE}$ plasmalogens ( $\mathrm{PE}(\mathrm{p}-$ 16:0/18:2) and $\mathrm{PE}(\mathrm{p}-16: 0 / 18: 1))$ were associated with both tumor areas and areas of inflammation, whereas PC plasmalogens are exclusively abundant in areas of usual necrosis.

Although plasmalogens represent up to $20 \%$ of the total phospholipid mass in humans [7], found in plasma, different tissues and exosomes secreted by the colorectal cancer cell line [92], they have been excluded from profiles presented in many other studies in spite of the fact that the alterations of these active molecules are known to occur.

Altered metabolism of plasmalogens has also been reported in other cancers, such as breast, ovarian and lung cancer. Merchant et al. [85], showed that PC plasmalogens were increased in neoplastic human breast tissue compared to benign tissue and LPC was significantly depressed in benign tissue compared to normal tissue. PL indices computed to further characterize the three tissue groups showed PC plasmalogens/PC elevated in malignant tissue compared to benign tissue and PE plasmalogens/PE depressed in malignant tissue compared to noninvolved tissue. These findings support previous investigations reporting that the alkyl-phospholipid analogues of PC are released by malignant tissues and that levels of PE are elevated in malignant tissues.

Smith et al. [93] investigate the suitability of a lipid tumor marker derived from ether-linked PL in normal, benign and neoplastic samples from human breast, lung and prostate tissues. They observed that a biochemical marker derived from PE plasmalogens provides a reliable index capable of distinguishing between benign and neoplastic tissues and it correlates linearly with metastases spreading in vivo. A notable decrease of relative abundances of ether and vinylether (PIs) lipid species was detected for PEs, but no difference is apparent for PCs in tissues of breast cancer patients [94]. Recently, a lipidomics study on breast cancer patients identified increased plasma ether-linked phosphatidylcholine species as a diagnostic marker for breast cancer [95]. Compared to that found in benign patients, the plasma concentration of LPC and CE were observed to decrease in cancer patients, while PC and ether-linked phosphatidylcholine were increased. The results showed that lipid profiles may be a promising avenue for the investigation of diagnostic biomarkers of breast cancer.

Opposing trends are observed in ovarian cancer. Hou et al. [96] described that the epithelial ovarian cancer patients have reduced levels of plasmalogens compared with benign ovarian tumors and normal controls. The decreased PC and PE plasmalogens levels in these patients suggested that most cancer cells might exhibit elevated oxidative stress, which is consistent with previous findings that oxidative stress is associated with cancer progression [97].

\section{Anti-tumor properties of synthetic plasmalogens and analogues}

Ether lipids have been shown to have anti-tumor properties, including reduction of tumor cell invasion and inhibition of tumor metastases. It is proposed that these chemotherapeutic agents interfere with lipid homeostasis due to their similarity with endogenous PL, targeting membrane lipid rafts and altering lipid-linked signalling, hence leading to apoptosis [98, 99]. Typical representatives of this group are ether PL ET-18- $\mathrm{OCH}_{3}$ (edelfosine) and BM 41.440 (ilmofosine) as well as hexadecylphosphocholine (miltefosine) [100]. Encouraging results have been found with all these compounds and novel, promising analogues such as erucylphosphocholine (ErPC) and its homocholine analogue erufosine (ErPC3) also hold promise as a single-agent (monotherapy) or in combination regimens [101]. Several studies combining the more recent ether lipids derivatives with diverse antineoplastic agents provide clinically significant benefits [99]. Shin et al. [102] described the synthetic pathway applied to the synthesis of 1-O-1'- (Z) -hexadecenyl-2-O-methyl-rac-glycero-3phosphocholine, the Z-vinyl ether analogue of ET-18$\mathrm{OMe}$, which shows significant antitumor activity in pancreatic tumor cells. Also, Bittman et al. [103] reported the incorporation of a cis-O-vinyl linkage into the $s n-1$ position of glycerol of plasmalogens to synthesize a new antitumor ether lipid analogue of ET-18- $\mathrm{OCH}_{3}$.

The expression of plasmalogens is characteristic for tumorigenicity and an abnormal level of these glycerolipids was identified in various cancerous membranes. Flasinski et al. [104] showed that the addition of ether lipids (PAF, lyso-PAF and edelfosine) destabilizes the 
films on model membranes with higher choline plasmalogens content (HL-60 and normal + PC-plasma model membranes) and strengthens the interactions in systems lacking choline plasmalogens (normal leucocytes model membrane) or of lower choline plasmalogens level (K562). It should be pointed out that cell membranes sensitive to edelfosine have a lower level of cholesterol and are enriched by choline plasmalogens (HL-60), while insensitive species have a higher sterol level and simultaneously lack plasmalogens (normal erythrocytes) or are of decreased choline plasmalogens level compared to the sensitive cells (e.g. K-562 cells). Interestingly, the level of choline plasmalogens in cells insensitive to the effect of edelfosine, normal lymphocytes and K-562 cells is lower when compared with HL-60 cells [105].

\section{Conclusion and perspective}

Changes in plasmalogens levels were shown in this review to be exceptionally significant in biofluids and tissues of various cancer types compared with controls, which makes this category of plasmalogens good candidates as potential cancer biomarkers. This review aimed to give an overview of the current knowledge in this field with a focus on the involvement of plasmalogens in cancer. Although there is a growing body of evidence of their involvement in human diseases, many studies do not report the existence of these molecules in plasma or tissue samples from GI cancer patients. Lipidomics has just begun to enter the field of cancer diagnostics and tumor biology and the evolution of lipidomic analysis with new highthroughput, high sensitivity methods such as massspectrometry has made major advances in the plasmalogen field possible, by enabling detailed analyses of lipid species concentrations. Also, sophisticated statistical softwares (chemometrics) have enabled meaningful information extraction from the lipidomic data. In the near future this will lead to the identification and validation of novel, more specific biomarkers for disease detection and monitoring. The published data shows that plasmalogen levels in tissue or plasma are altered in several types of cancer. In this context, further studies should be carried out to evaluate the role of plasmalogens as potential biomarkers in patients with GI cancer and also to determine whether targeted inhibition of the vinyl-ether lipid synthetic pathway could treat these malignancies.

\section{Additional file}

Additional file 1: Supplementary material. (DOCX $13 \mathrm{~kb}$ )

\section{Abbreviations}

${ }^{31}$ P NMR: Phosphorus nuclear magnetic resonance spectroscopy;

AA: Arachidonic acid; ADHAP-S: Alkyl dihydroxyacetone phosphate synthase; AGPS: Alkylglyceronephosphate synthase; DESI: Desorption electrospray ionization; DHAP: Dihydroxyacetone phosphate; DHAPAT: Dihydroxyacetone phosphate acyltransferase; DNPH: Dinitrophenylhydrazine; ESI: Electrospray ionization; FAR1/ FAR2: Acyl-CoA reductase 1 and 2; FDA: Food \& Drug Administration; Fl-FTICRMS: Flow-injection fourier transform ion cyclotron resonance mass spectrometry; FI-MS/MS: Flow-injection tandem mass spectrometry mass spectrometry; GCMS: Gas chromatography-mass spectrometry; GC-TOF-MS: Gas chromatography time-of-flight mass spectrometry; Gl: Gastrointestinal; GPL: Glycerophospholipids; HPLC: High performance liquid chromatography; LC-MS: Liquid chromatographymass spectrometry; LC-QqTOF-MS: Liquid chromatography quadrupole time-offlight mass spectrometry; LPC: Lysophosphatidylcholine; MALDI: Matrix-assisted laser desorption and ionization; MALDI-FTICR-MS: Matrix-assisted laser desorption and ionization fourier transform ion cyclotron resonance mass spectrometry; MALDI-MSI: Matrix-assisted laser desorption/ionization mass spectrometry imaging; MALDI-TOF-MS: Matrix-assisted laser desorption and ionization time-offlight mass spectrometry; MS: Mass spectrometry; MS/MS: Tandem mass spectrometry; PA: Phosphatidic acid; PC: Phosphatidylcholine;

PE: Phosphatidylethanolamine; PG: Phosphatidylglycerol;

PI: Phosphatidylinositol; PL: Phospholipids; PLA2: Phospholipase A2;

PS: Phosphatidylserine; TLC: Thin-layer Chromatography

\section{Acknowledgments}

This work has been supported by grants from Fapesp (2016/11905-2) and Capes.

Funding

This work was supported by Fapesp (2016/11905-2) and Capes.

Availability of data and materials

Not applicable.

Authors' contributions

POC and MCFM conception and design of research; POC and MCFM drafted of manuscript; POC, MCFM, GCM and DGP revised and approved final

version of manuscript.

Ethics approval and consent to participate

Not applicable.

Consent for publication

Not applicable.

\section{Competing interests}

The authors declare that they have no competing interests.

\section{Publisher's Note}

Springer Nature remains neutral with regard to jurisdictional claims in published maps and institutional affiliations.

Received: 4 September 2017 Accepted: 19 February 2018

Published online: 07 March 2018

\section{References}

1. Ferlay J, Soerjomataram I, Dikshit R, Eser S, Mathers C, Rebelo M, Parkin DM, Forman D, Bray F. Cancer incidence and mortality worldwide: sources, methods and major patterns in GLOBOCAN 2012. Int J Cancer. 2015;136: 359-86. https://doi.org/10.1002/ijc.29210.

2. Loizides-Mangold U. On the future of mass-spectrometry-based lipidomics. FEBS J. 2013;280(12):2817-29. https://doi.org/10.1111/febs.12202.

3. Fhaner C, Liu S, Ji H, Simpson R, Reid G. Comprehensive lipidome profiling of isogenic primary and metastatic colon adenocarcinoma cell lines. Anal Chem. 2012;84(21):8917-26. https://doi.org/10.1021/ac302154g.

4. Luo X, Cheng C, Tan Z, Li N, Tang M, Yang L, Cao Y. Emerging roles of lipid metabolism in cancer metastasis. Mol Cancer. 2017;16(1):76. https://doi.org/ 10.1186/s12943-017-0646-3.

5. Dueck D, Chan M, Tran K, Wong J, Jay F, Littman C, et al. The modulation of choline phosphoglyceride metabolism in human colon cancer. Mol Cell Biochem. 1996;162(2):97-103. https://doi.org/10.1007/BF00227535.

6. Bandu R, Mok H, Kim K. Phospholipids as cancer biomarkers: mass spectrometry-based analysis. Mass Spectrom Rev. 2016; https://doi.org/10. 1002/mas.21510.

7. Braverman N, Moser A. Functions of plasmalogen lipids in health and disease. Biochim Biophys Acta. 2012;1822(9):1442-52. https://doi.org/10. 1016/j.bbadis.2012.05.008. 
8. Snyder F. The ether lipid trail: a historical perspective. Biochim Biophys Acta. 1999;1436(3):265-78. https://doi.org/10.1016/S0005-2760(98)00172-6.

9. Han X. Lipidomics for studying metabolism. Nat Rev Endocrinol. 2016;12(11): 668-79. https://doi.org/10.1038/nrendo.2016.98.

10. Pourhoseingholi MA, Vahedi M, Baghestani AR. Burden of gastrointestinal cancer in Asia: an overview. Gastroenterol Hepatol Bed Bench. 2015:8(1):19-27.

11. World Health Organization. Cancer. [Internet], (2017) [cited 28 Aug 2017 ]. Available from: http://www.who.int/mediacentre/factsheets/fs297/en/.

12. Yan G, Li L, Zhu B, Li Y. Lipidome in colorectal cancer. Oncotarget. 2016;7: 33429-39. https://doi.org/10.18632/oncotarget.7960.

13. Das V, Kalita J, Pal M. Predictive and prognostic biomarkers in colorectal cancer: a systematic review of recent advances and challenges. Biomed Pharmacother. 2017:87:8-19. https://doi.org/10.1016/j.biopha.2016.12.064.

14. Yang K, Han X. Lipidomics: techniques, applications, and outcomes related to biomedical sciences. Trends Biochem Sci. 2016;41:954-69. https://doi.org/ 10.1016/j.tibs.2016.08.010

15. Perrotti F, Rosa C, Cicalini I, P Sacchetta P, Del Boccio GD, Genovesi D, Pieragostino D. Advances in lipidomics for cancer biomarkers discovery. Inter J Mol Sci. 2016;17(12):1992. https://doi.org/10.3390/ijms17121992.

16. Li M, Fan P, Wang Y. Lipidomics in health and diseases - beyond the analysis of lipids. Glycomics Lipidomics. 2015;5:1-15. https://doi.org/10.4172/2153-0637.1000126.

17. Fahy E, Cotter D, Sud M, Subramaniam S. Lipid classification, structures and tools. Biochim Biophys Acta. 2011;1811(11):637-47. https://doi.org/10.1016/j. bbalip.2011.06.009.

18. Brügger B. Lipidomics: analysis of the lipid composition of cells and subcellular organelles by electrospray ionization mass spectrometry. Annu Rev Biochem. 2014;83(1):79-98. https://doi.org/10.1146/annurev-biochem060713-035324.

19. Lipid Maps Lipidomics Gateway: Home [Internet]. Lipidmaps.org. (2017) [cited 20 May 2017]. Available from: http://www.lipidmaps.org.

20. Vance JE. Membrane lipid biosynthesis. Wiley Online Library, (2001). Available from: http://onlinelibrary.wiley.com/doi/10.1038/npg.els.0001391/ abstract.

21. Hossain M, Mineno K, Katafuchi T. Neuronal orphan G-protein coupled receptor proteins mediate Plasmalogens-induced activation of ERK and Akt signaling. PLoS One. 2016;11(3):1-14. https://doi.org/10.1371/journal.pone.0150846.

22. Onodera T, Futai E, Kan E, Abe N, Uchida T, Kamio Y, Kaneko J. Phosphatidylethanolamine plasmalogen enhances the inhibiting effect of phosphatidylethanolamine on secretase activity. J Biochem. 2014;157(5): 301-9. https://doi.org/10.1093/jb/mvu074.

23. Maeba R, Nishimukai M, Sakasegawa S, Sugimori D, Hara H. Plasma/serum plasmalogens: methods of analysis and clinical significancee. Adv Clin Chem. 2015;70:31-91. https://doi.org/10.1016/bs.acc.2015.03.005.

24. FDA. U S Food and Drug Administration Home Page [Internet]. Fda.gov. (2017) [cited 20 May 2017]. Available from: http://www.fda.gov.

25. Newton K, Newman W, Hill J. Review of biomarkers in colorectal cancer. Color Dis. 2011;14(1):3-17. https://doi.org/10.1111/j.1463-1318.2010.02439.x

26. Henry NL, Hayes DF. Cancer biomarkers. Mol Oncol. 2012;6:140-6. https:// doi.org/10.1016/j.molonc.2012.01.010.

27. Nordberg G. Biomarkers of exposure, effects and susceptibility in humans and their application in studies of interactions among metals in China. Toxicol Lett. 2010;192(1):45-9. https://doi.org/10.1016/j.toxlet.2009.06.859.

28. Huang Z, Huang D, Ni S, Peng Z, Sheng W, Du X. Plasma microRNAs are promising novel biomarkers for early detection of colorectal cancer. Int J Cancer. 2010;127(1):118-26. https://doi.org/10.1002/ijc.25007.

29. Goossens N, Nakagawa S, Sun X, Hoshida Y. Cancer biomarker discovery and validation. Transl Cancer Res. 2015;4(3):256-69. https://doi.org/10.3978/j. issn.2218-676X.2015.06.04.

30. Sideris M, Papagrigoriadis S. Molecular biomarkers and classification models in the evaluation of the prognosis of colorectal cancer. Anticancer Res. 2014:34(1):2061-8.

31. Li M, Yang L, Bai Y, Liu H. Analytical methods in lipidomics and their applications. Anal Chem. 2014;86(1):161-75. https://doi.org/10.1021/ac403554h.

32. Zoeller R, Lake A, Nagan N, Gaposchkin D, Legner M, Lieberthal W. Plasmalogens as endogenous antioxidants: somatic cell mutants reveal the importance of the vinyl ether. Biochem J. 1999;338(3):769-76. https://doi. org/10.1042/bj3380769.

33. Yamashita S, Honjo A, Aruga M, Nakagawa K, Miyazawa T. Preparation of marine plasmalogen and selective identification of molecular species by LC-MS/MS. Journal of Oleo Science. 2014;63(5):423-30. https://doi. org/10.5650/jos.ess 13188 .
34. Wallner S, Schmitz G. Plasmalogens the neglected regulatory and scavenging lipid species. Chem Phys Lipids. 2011;164:573-89. https://doi. org/10.1016/j.chemphyslip.2011.06.008.

35. Hu C, Wang M, Han X. Shotgun lipidomics in substantiating lipid peroxidation in redox biology: methods and applications. Redox Biol. 2017; 12:946-55. https://doi.org/10.1016/j.redox.2017.04.030.

36. Rintala J, Seemann R, Chandrasekaran K, Rosenberger TA, Chang L, Contreras MA, Rapoport S, Chang MCJ. 85 kDa cytosolic phospholipase A2 is a target for chronic lithium in rat brain. Neuroreport. 1999;10(18):3887-90. https://doi.org/10.1097/00001756-199912160-00030.

37. Lohner K. Is the high prospensity of ethanolamine plasmalogens to form non-lamellar lipid structures manifested in the properties of biomembranes? Chem Phys Lipids. 1996;81(2):167-84. https://doi.org/10.1016/00093084(96)02580-7.

38. Lohner K, Hermetter A, Paltauf F. Phase behavior of ethanolamine plasmalogen. Chem Phys Lipids. 1984;34(2):163-70. https://doi.org/10.1016/ 0009-3084(84)90041-0.

39. Han X, Gross RW. Nonmonotonic alterations in the fluorescence anisotropy of polar head group labeled fluorophores during the lamellar to hexagonal phase transition of phospholipids. Biophys J. 1992;63(2):309-16. https://doi. org/10.1016/S0006-3495(92)81616-8.

40. Fuchs B. Analytical methods for (oxidized) plasmalogens: methodological aspects and applications. Free Radic Res. 2015;49(5):599-617. https://doi.org/ 10.3109/10715762.2014.999675.

41. Nagan N, Zoeller R. Plasmalogens: biosynthesis and functions. Prog Lipid Res. 2001;40(3):199-229. https://doi.org/10.1016/S0163-7827(01)00003-0.

42. Engelmann B. Plasmalogens: targets for oxidants and major lipophilic antioxidants. Biochem Soc Trans. 2004;32(1):147-50. https://doi.org/10.1042/ bst0320147.

43. Leßig J, Fuchs B. Plasmalogens in biological systems: their role in oxidative processes in biological membranes, their contribution to pathological processes and aging and plasmalogen analysis. Curr Med Chem. 2009; 16(16):2021-41. http://dx.doi.org/10.2174/092986 0709788682164.

44. Otoki Y, Kato S, Kimura F, Furukawa K, Yamashita S, Arai H, et al. Accurate quantitation of choline and ethanolamine plasmalogen molecular species in human plasma by liquid chromatography-tandem mass spectrometry. J Pharm Biomed Anal. 2017;134:77-85. https://doi. org/10.1016/j.jpba.2016.11.019.

45. Zhan Y, Wang L, Liu J, Ma K, Liu C, Zhang Y, Zou W. Choline Plasmalogens isolated from swine liver inhibit hepatoma cell proliferation associated with Caveolin-1/Akt signaling. PLoS One. 2013;8(10):eE77387. https://doi.org/10. 1371/journal.pone.0077387.

46. Brites $P$, Mooyer $P$, El Mrabet $L$, Waterham H, Wanders R. Plasmalogens participate in very-long-chain fatty acid-induced pathology. Brain. 2008; 132(2):482-92. https://doi.org/10.1093/brain/awn295.

47. Honsho M, Abe Y, Fujiki Y. Plasmalogen biosynthesis is spatiotemporally regulated by sensing plasmalogens in the inner leaflet of plasma membranes. Sci Rep. 2017;7:43936. https://doi.org/10.1038/srep43936.

48. Brites $P$, Waterham $H$, Wanders $R$. Functions and biosynthesis of plasmalogens in health and disease. Biochim Biophys Acta. 2004;1636(2-3): 219-31. https://doi.org/10.1016/j.bbalip.2003.12.010.

49. Goldfine $H$. The appearance, disappearance and reappearance of plasmalogens in evolution. Prog Lipid Res. 2010;49(4):493-8. https://doi.org/ 10.1016/j.plipres.2010.07.003

50. Honsho M, Asaoku S, Fujiki Y. Posttranslational regulation of fatty acyl-CoA reductase 1, Far1, controls ether Glycerophospholipid synthesis. J Biol Chem. 2010;285(12):8537-42. https://doi.org/10.1074/ jbc.M109.083311.

51. Jurkowitz-Alexander MS, Hirashima Y, Horrocks LA. Coupled enzyme assays for phospholipase activities with plasmalogen substrates. Methods Enzymol. 1991;197:79-89. https://doi.org/10.1016/0076-6879(91)97135-L.

52. Wu L, Pfeiffer D, Calhoon E, Madiai F, Marcucci G, Liu S, et al. Purification, identification, and cloning of Lysoplasmalogenase, the enzyme that catalyzes hydrolysis of the vinyl ether bond of Lysoplasmalogen. J Biol Chem. 2011; 286(28):24916-30. https://doi.org/10.1074/jbc.M111.247163.

53. Murakami M, Kudo I. Phospholipase A2. J Biochem. 2002;131(3):285-92. https://doi.org/10.1093/oxfordjournals.jbchem.a003101.

54. Mankidy R, Ahiahonu PW, Ma H, Ayasinghe JD, Ritchie SA, Khan MA, SuMyat KK, Wood PL, Goodenowe DB. Membrane plasmalogen composition and cellular cholesterol regulation: a structure activity study. Lipids Health Dis. 2010;9:62. https://doi.org/10.1186/1476-511X-9-62. 
55. André A, Juanéda P, Sébédio J, Chardigny J. Plasmalogen metabolismrelated enzymes in rat brain during aging: influence of $\mathrm{n}-3$ fatty acid intake. Biochimie. 2006;88(1):103-11. https://doi.org/10.1016/j.biochi.2005.06.010.

56. Spector A, Yorek M. Membrane lipid composition and cellular function. J Lipid Res. 1985;26(9):1015-35.

57. Demopoulos C, Pinckard R, Hanahan D. Platelet-activating factor. Evidence for 1-0-alkyl-2-acetyl-sn-glyceryl-3-phosphorylcholine as the active component (a new class of lipid chemical mediators). J Biol Chem. 1979; 254(19):9355-8.

58. Fernández R, Garate J, Lage S, Terés S, Higuera M, Bestard-Escalas J, et al. Identification of biomarkers of necrosis in xenografts using imaging mass spectrometry. J Am Soc Mass Spectrom. 2015;27(2):244-54. https://doi.org/ 10.1007/s13361-015-1268-X.

59. Broniec A, Klosinski R, Pawlak A, Wrona-Krol M, Thompson D, Sarna T. Interactions of plasmalogens and their diacyl analogs with singlet oxygen in selected model systems. Free Radic Biol Med. 2011;50(7):892-8. https://doi org/10.1016/j.freeradbiomed.2011.01.002

60. Sindelar P, Guan Z, Dallner G, Ernster $L$. The protective role of plasmalogens in iron-induced lipid peroxidation. Free Radic Biol Med. 1999;26(3-4):318-24. https://doi.org/10.1016/S0891-5849(98)00221-4.

61. Zemski Berry K, Murphy R. Free radical oxidation of plasmalogen glycerophosphocholine containing esterified docosahexaenoic acid: structure determination by mass spectrometry. Antioxid Redox Signal. 2005; 7(1-2):157-69. https://doi.org/10.1089/ars.2005.7.157.

62. Hahnel D, Huber T, Kurze V, Beyer K, Engelmann B. Contribution of copper binding to the inhibition of lipid oxidation by plasmalogen phospholipids. Biochem J. 1999;340(2):377-83. https://doi.org/10.1042/0264-6021:3400377.

63. Fhaner C, Liu S, Zhou X, Reid G. Functional group selective derivatization and gas-phase fragmentation reactions of plasmalogen glycerophospholipids. Mass Spectrometry. 2013;2:S0015. https://doi.org/10. 5702/massspectrometry.

64. Folch $\mathrm{H}$, Less $\mathrm{M}$, Stanley HA. A simple method for isolation and purification of total lipids from animal tissues. J Biol Chem. 1957;226:497-9. https://doi org/10.1371/journal.pone.0020510.

65. Fuchs B, Süß R, Schiller J. An update of MALDI-TOF mass spectrometry in lipid research. Prog Lipid Res. 2010;49(4):450-75. https://doi.org/10.1016/j. plipres.2010.07.001.

66. Nimptsch A, Fuchs B, Süß R, Zschörnig K, Jakop U, Göritz F, Schiller J, Müller K. A simple method to identify ether lipids in spermatozoa samples by MALDI-TOF mass spectrometry. Anal Bioanal Chem. 2013;405(21):6675-82. https://doi.org/10.1007/s00216-013-7147-z.

67. Maeba R, Ueta N. Determination of choline and ethanolamine plasmalogens in human plasma by HPLC using radioactive triiodide (1-) ion (12513-). Anal Biochem. 2004;331(1):169-76. https://doi.org/10.1016/j.ab.2004.05.030.

68. Murphy E, Stephens R, Jurkowitz-Alexander M, Horrocks L. Acidic hydrolysis of plasmalogens followed by high-performance liquid chromatography. Lipids. 1993;28(6):565-8. https://doi.org/10.1007/BF02536090.

69. Patton GM, Robins SJ. Separation and quantification of phospholipid classes by HPLC. Lipoproteins protocols. Methods Mol Biol. 1998;110:193-215.

70. Mawatari S, Okuma Y, Fujino T. Separation of intact plasmalogens and all other phospholipids by a single run of high-performance liquid chromatography. Anal Biochem. 2007;370(1):54-9. https://doi.org/10.1016/j.ab.2007.05.020.

71. Busik JV, Reid GE, Lydic TA. Global analysis of retina lipids by complementary precursor ion and neutral loss mode tandem mass spectrometry. Methods Mol Biol. 2009;579:33-70. https://doi.org/10.1007/ 978-1-60761-322-0_3.

72. Wacker BK, Albert CJ, Ford BA, Ford DA. Strategies for the analysis of chlorinated lipids in biological systems. Free Radic Biol Med. 2013;59:92-9. https://doi.org/10.1016/j.freeradbiomed.2012.06.013.

73. Otoki Y, Nakagawa K, Kato S, Miyazawa T. MS/MS and LC-MS/MS analysis of choline/ethanolamine plasmalogens via promotion of alkali metal adduct formation. J Chromatogr B Analyt Technol Biomed Life Sci. 2015;1004:85-92. https://doi.org/10.1016/j.jchromb.2015.09.012.

74. Fuck B. Analytical methods for (oxidized) plasmalogens: methodological aspects and applications. Free Radic Res. 2014;49(5):599-617. https://doi.org/ 10.3109/10715762.2014.999675

75. Ritchie SA, Akita H, Takemasa I, Eguchi H, Pastural E, Nagano H, Monden M, Doki Y, Mori M, Jin W, Sajobi TT, Jayasinghe D, Chitou B, Yamazaki Y, Hite T, Goodenowe DB. Metabolic system alterations in pancreatic cancer patient serum: potential for early detection. BMC Cancer. 2013;13(416):1-17. https:// doi.org/10.1186/1471-2407-13-416.
76. Leßig J, Gey C, Süß R, Schiller J, Glander HJ, Arnhold J. Analysis of the lipid composition of human and boar spermatozoa by MALDI-TOF mass spectrometry, thin layer chromatography and 31P NMR spectroscopy. Comp Biochem Physiol B Biochem Mol Biol. 2004;137(2):265-77. https://doi.org/10. 1016/j.cbpc.2003.12.001.

77. Merchant TE, Minsky BD, Lauwers GY, Diamantis PM, Haida T, Glonek T. Esophageal cancer phospholipids correlated with histopathologic findings: a 31P NMR study. NMR Biomed. 1999;12(4):1-5. http://dx.doi.org/10.1002/nbm. 1940060304.

78. Snyder F, Wood R. Alkyl and alk-1-enyl ethers of glycerol in lipids from normal and neoplastic human tissues. Cancer Res. 1969;29(1):251-7.

79. Howard BV, Morris HP, Bailey JM. Ether-lipids, - glycerol phosphate dehydrogenase and growth rate in tumors and cultured cells. Cancer Res. 1972;32(7):1533-8.

80. Albert DH, Anderson CE. Ether-linked glycerolipids in human brain tumors. Lipids. 1977;12(2):188-92

81. Roos DS, Choppin PW. Tumorigenicity of cell lines with altered lipid composition. Proc Natl Acad Sci U S A. 1984;81:7622-6.

82. Misra S, Ghosh A, Varticovski L. Naturally occurring ether linked phosphatidylcholine activates phosphatidylinositol 3-kinase and stimulates cell growth. J Cell Biochem. 1994;55(1):146-53. https://doi.org/10.1002/jcb. 240550116.

83. Benjamin DI, Cozzo A, Ji X, Roberts LS, Louie SM, Mulvihill MM, Luo K, Nomura DK. Ether lipid generating enzyme AGPS alters the balance of structural and signaling lipids to fuel cancer pathogenicity. Proc Natl Acad Sci U S A. 2013;110(37):14912-7. https://doi.org/10.1073/pnas.1310894110.

84. Piano V, Benjamin DI, Valente S, Nenci S, Mai A, Aliverti A, Nomura DK, Mattevi A. Discovery of inhibitors for the ether lipid-generating enzyme AGPS as anti-cancer agents. ACS Chem Biol. 2015;10(11):2589-97. https:// doi.org/10.1021/acSchembio.5b00466

85. Merchant T, Kasimos J, de Graaf P, Minsky B, Gierke L, Glonek T. Phospholipid profiles of human colon cancer using 31P magnetic resonance spectroscopy. Int J Color Dis. 1991;6(2):121-6. https://doi.org/10.1007/BF00300208.

86. Christen S, Hagen TM, Shigenaga MK, Ames BN. Chronic inflammation, mutation and cancer. In: Parsonnet J, editor. Microbes and malignancy: infection as a cause of human cancer. New York: Oxford University Press; 1999. p. 35-88.

87. Gerbig S, Golf O, Balog J, Denes J, Baranyai Z, Zarand A, Raso E, Timar J, Takats Z. Analysis of colorectal adenocarcinoma tissue by desorption electrospray ionization mass spectrometric imaging. Anal Bioanal Chem. 2012;403:2315-25. https://doi.org/10.1007/s00216-012-5841-x.

88. Jun L, Can-Qun L, Lei X, Hong Y. Plasma content variation and correlation of plasmalogen and GIS, TC and TPL in gastric carcinoma patients: a comparative study. Med Sci Monit Basic Res. 2015;21:157-60. https:/doi.org/ 10.12659/MSMBR.893908.

89. Sugiura T, Fukuda T, Masuzawa Y, Waku K. Ether lysophospholipid-induced production of platelet-activating factor in human polymorphonuclear leukocytes. Biochim Biophys Acta. 1990;1047:223-32. https://doi.org/10. 1016/0005-2760(90)90520-8.

90. Schrakamp G, Schutgens RB, Wanders RJ, Heymans HSA, Tager JM, Bosch HVD. The cerebro-hepato-renal (Zellweger) syndrome. Impaired de novo biosynthesis of plasmalogens in cultured skin fibroblasts. Biochim Biophys Acta. 1985:833(1):170-4. https://doi.org/10.1016/0005-2760(85)90266-8.

91. Patterson NH, Alabdulkarim B, Lazaris A, Thomas A, Marcinkiewicz MM, Gao ZH, Vermeulen PB, Chaurand P, Metrakos P. Assessment of pathological response to therapy using lipid mass spectrometry imaging. Sci Rep. 2016; 6(36814). https://doi.org/10.1038/srep36814.

92. Lydic TA, Townsend S, Adda CG, Collins C, Mathivanan S, Reid GE. Rapid and comprehensive 'shotgun' lipidome profiling of colorectal cancer cell derived exosomes. Methods. 2015;87:83-95. https://doi.org/10.1016/j.ymeth.2015.04.014.

93. Smith R, Lespi P, Luca M, Bustos C, Marra F, Alaniz M, Marra C. A reliable biomarker derived from plasmalogens to evaluate malignancy and metastatic capacity of human cancers. Lipids. 2008;43(1):79-89. https://doi. org/10.1007/s11745-007-3133-6.

94. Cífková E, Holcapek M, Lísa M, Vrána D, Gatek J, Melichar B. Determination of lipidomic diferences between human breast câncer and surrounding normal tissues using HILIC-HPLC/ESI-MS and multivariate data analysis. Anal Bioanal Chem. 2015;407:991-1002. https://doi.org/10.1007/s00216-014-8272-z

95. Chen X, Chen H, Dai M, Ai J, Li Y, Mahon B, Dai S, Deng Y. Plasma lipidomics profiling identified lipid biomarkers in distinguishing early-stage breast cancer from benign lesions. Oncotarget. 2016;7(24):36622-31. 
96. Hou Y, Li J, Xie H, Sun F, Yang K, Wang J, Ke C, Lou G, Li K. Differentia plasma lipids profiling and lipid signatures as biomarkers in the early diagnosis of ovarian carcinoma using UPLC-MS. Metabolomics. 2016;12(18): 1-12. https://doi.org/10.1007/s11306-015-0891-7.

97. Siti HN, Kamisah Y, J Kamsiah J. The role of oxidative stress, antioxidants and vascular inflammation in cardiovascular disease (a review). Vasc Pharmacol. 2015;71:40-56. https://doi.org/10.1016/j.vph.2015.03.005.

98. Blitterswijk WJV, Verheij M. Anticancer mechanisms and clinical application of alkylphospholipids. Biochim Biophys Acta. 2013;1831:663-74. https://doi. org/10.1016/j.bbalip.2012.10.008.

99. Kostadinova A, Topouzova-Hristova T, Momchilova A, Tzoneva R, Berger MR. Antitumor lipids-structure, functions, and medical applications. Adv Protein Chem Struct Biol. 2015;101:27-66. https://doi.org/10.1016/bs.apcsb.2015.08.001.

100. Lohmeyer M, Bittman R. Antitumor ether lipids and alkylphosphocholines. Drugs Future. 1994;19:1021-37.

101. Ríos-Marco P, Marco C, Gálvez X, Jiménez-López JM, Carrasco MP. Alkylphospholipids: na update on molecular mechanisms and clinical relevance. Biochim Biophys Acta. 2017;1859:1657-67. https://doi.org/10. 1016/j.bbamem.2017.02.016.

102. Shin J, Qualls MM, Boomer JA, Robarge J, Thompson DH. An efficient new route to plasmenyl-type lipids: synthesis and cytotoxicity of a plasmenylcholine analogue of the antitumor ether lipid ET-18-OMe. J Am Chem Soc. 2001;123:508-9. https://doi.org/10.1021/ja005522t.

103. Bittman R, Qin D, Wong DA, Tigyi G, Samadder P, Arthur G. Synthesis and antitumor properties of a plasmalogen methyl ether analogue. Tetrahedron. 2001:57:4277-82. https://doi.org/10.1016/S0040-4020(01)00371-4.

104. Flasiński M, Hąc-Wydro K, Wydro P, Dynarowicz-Łątka P. Influence of platelet-activating factor, lyso-platelet-activating factor and edelfosine on Langmuir monolayers imitating plasma membranes of cell lines differing in susceptibility to anti-cancer treatment: the effect of plasmalogen level. J R Soc Interface. 2014;11:1-11. https://doi.org/10.1098/rsif.2013.1103.

105. Chabot MC, Wykle RL, Modest EJ, Daniel LW. Correlation of ether lipid content of human leukemia cell lines and their susceptibility to 1-OOctadecyl-1-Omethyl-rac-glycero-S-phosphocholine. Cancer Res. 1989;49(16):4441-5.

106. Lin $\mathrm{HJ}$, Wu PC, Ho JCl. The ether lipid tumour marker in human liver with hepatocellular carcinoma. Br J Cancer. 1980;41(2):320-4.

107. Liesenfeld D, Grapov D, Fahrmann J, Salou M, Scherer D, Toth R, et al. Metabolomics and transcriptomics identify pathway differences between visceral and subcutaneous adipose tissue in colorectal cancer patients: the ColoCare study. Am J Clin Nutr. 2015;102(2):433-43. https://doi.org/10.3945/ ajcn.114.103804.

\section{Submit your next manuscript to BioMed Central and we will help you at every step:}

- We accept pre-submission inquiries

- Our selector tool helps you to find the most relevant journal

- We provide round the clock customer support

- Convenient online submission

- Thorough peer review

- Inclusion in PubMed and all major indexing services

- Maximum visibility for your research

Submit your manuscript at www.biomedcentral.com/submit 